\title{
Degradation Pattern of Textile Effluent by Using Bio and Sono Chemical Reactor
}

\author{
Basem Mohammed Al-Sakkaf $\mathbb{D}^{1},{ }^{1}$ Sadia Nasreen ${ }^{(D)}{ }^{2}$ and Naeem Ejaz ${ }^{1}$ \\ ${ }^{1}$ Department of Civil Engineering, University of Engineering and Technology, Taxila 47080, Pakistan \\ ${ }^{2}$ Department of Environmental Engineering, University of Engineering and Technology, Taxila 47080, Pakistan \\ Correspondence should be addressed to Sadia Nasreen; sadia.nasreen@uettaxila.edu.pk
}

Received 23 November 2019; Revised 24 January 2020; Accepted 17 February 2020; Published 30 March 2020

Guest Editor: Fada Feng

Copyright ( $) 2020$ Basem Mohammed Al-Sakkaf et al. This is an open access article distributed under the Creative Commons Attribution License, which permits unrestricted use, distribution, and reproduction in any medium, provided the original work is properly cited.

\begin{abstract}
The research study was conducted to design the ultrasonic-assisted electrochemical reactor and the bioreactor/filter to evaluate the potential applicability of biological trickling filter system and to compare the efficiency of two reactors such as SER and TF for the treatment of textile industry effluents. Also the study to design Sonoelectrolytic process for wastewater treatment of textile industry containing strong color, high temperature, suspended particles and dissolved solid particles has been conducted. Effect to environment and health is caused by oxygen demand (BOD), high chemical oxygen demand (COD). The percentage removal efficiency for wastewater treatment of textile industry by using sonoelectrolytic reactor (SER) was found to be higher than $95 \%$ at temperature of $25^{\circ} \mathrm{C}$ and a $\mathrm{pH}$ value of 8.9 , while for trickling filter (TF), having adsorbent as a filter medium, efficiency was found to be $95 \%$, and optimum conditions obtained were applied for the treatment of different dye samples. Based on experimental outcomes, it is determined that treatment through SER is done faster than trickling filter because in TF the adsorbent capacity decreases with time and is a time-consuming process, but the chance of deposition on electrodes also increases in SER, so both these processes can yield better results if these problems are eliminated.
\end{abstract}

\section{Introduction}

In the last few years, wastewater from the textile industry has become a big problem which causes an increase in the concentration of environmental pollution in industrial cities, which in turn represents environmental risks [1]. Released wastewater in the textile industry and the chemical dyes can be considered as an important environmental concern, as about $200 \mathrm{~L}$ of water is used for every $1 \mathrm{~kg}$ of textile production [2]. Textile dyes contain a significant quantity of organic pollutants which are very difficult to degrade, and yearly around 5,000 tons of coloring materials are discharged into our environment [3]. The quantity of used water and the waste production both depend upon the amount of consumed water by several varieties of fabrics, and it changes from one textile industry to another due to reliance on the dyeing process. A rough estimation shows that the bleaching process requires $38 \%$ of water, printing requires $8 \%$, dyeing requires $16 \%$, boiler requires $14 \%$, and $24 \%$ is required for additional practices [4]. As a result of diverse processes, an enormous amount of hurtful effluents is discharged to the environment. Thus, textile effluent has a significant bit of colors and further destructive synthetic concoctions that are dangerous to the environment and are a long way from fulfilling the standards.

Textile industry effluent contains large number of harmful agents such as chemical oxygen demand (COD), biological oxygen demand (BOD), suspended particles, dissolved solid particles, chemicals, color and metals (zinc $(\mathrm{Zn})$, arsenic (As), copper $(\mathrm{Cu})$ and, chromium $(\mathrm{Cr}))$ which causes harm to humans and environment [5]. Coloring release contains a composite blend of colors, salts, and further synthetics, for example, surfactants and about $90 \%$ of the color and $80 \%$ of the salts are released in effluent [6]. Textile effluent is based upon manufacture products and chemicals and is classified in terms of acidic, 
basic, vat, and azo dyes while a variety of chemicals inculcated include detergents, caustic, latex, glues, and other chemicals [7]. Textile dyeing works utilizing various classes of chemical dye and extra synthetic substances produceing mixed wastewater [8]. The proficiency of the advanced oxidation process for degrading textile dyes containing the intractable compounds has been comprehensively acknowledged [9-11].

On estimation, most colors utilized in the textile business are effectively solvent in water and are nonbiodegradable due to their unyielding mixes and are a threat to the environment and could cause cancer [12]. The total input of dyes toward wastewater flow is about $15-20 \%$ and textile dyeing is contributing about $17 \%-20 \%$ of industrial discharge. There are about 72 toxic chemicals that have been recognized in water from textile dyeing, 30 of which cannot be removed easily [13].

Intense coloration of textile dyes poses high risks to aquatic life by creating obstruction to the light path to reach underwater. Many colors present in fiber effluent potentially cause cancer and mutation and are genotoxic [14]. Material coloring process incorporates different activities, for example, pretreatment, coloring, printing, and washing of pieces of clothing resulting into the generation of a lot of contaminated effluents. The transformation of fiber up to one ton produces about $230-270$ cubic meter of polluted water and is required to be cleaned before releasing into the environment [15]. Textile effluents as colors are the most dangerous compound blends found in fiber effluents and ought to be dealt with splendidly as their appearance in water bodies diminishes light invasion, blocking the photosynthesis of watery verdure [16, 17]. Photo-Chemical and ozone chemical treatment processes are collectively resulted as the quick degradation process with better efficiency but the expense of this method is high and is not powerful for treating the entire azo dyes. Also, the generation of various radicals with the expansion of substance reagents causes minor drop of TOC and COD qualities creating the lackluster however degradable polluted water [18].

Industrial dyes involve aromatic compounds in their chemical composition. These dyes are synthesized by chemical combination of altered functional group and relocated electrons. The chromogen comprises a fragrant structure regularly relying upon benzene, naphthalene, or anthracene. The chromophore arrangements are, the azo gathering $(-\mathrm{N}=\mathrm{N}-)$, ethylene gathering $(=\mathrm{C}=\mathrm{C}=)$, methine bunch $(-\mathrm{CH}=)$, carbonyl gathering $(=\mathrm{C}=\mathrm{O})$ and chinoid gatherings. Azo colors might be poisonous after metabolic decrease of the azo bond, creating sweetsmelling amines. The auxo chrome bunches are ionizable gatherings that present coupling limit to the dyematerial. The standard auxo chrome bunches are- $\mathrm{NH}_{2}$ (amino), - $\mathrm{COOH}$ (carboxyl),- $-\mathrm{SO}_{3} \mathrm{H}$ (sulphonate), and - $\mathrm{OH}$ (hydroxyl) [19]. Dyes are classified as natural and synthetic based upon application characteristics and chemical structure. Different treatment techniques of textile wastewater have been proposed in the literature [20].
Fabric industry is perhaps the biggest business on the planet, and various textures, for example, silk, cotton, and fleece are all prerestored, handled, and hued, utilizing a lot of water and a range of chemicals after treatment, so there is a need to comprehend the textile effluent well overall.

1.1. Classification of Dye Removal Techniques. There are several dye removal techniques (Figure 1) which are classified as chemical, physical, and biological methods. Physical method for removing dyes includes adsorption, ion exchange, and filtration/coagulation methods [21, 22], while chemical methods include ozonisation, Fenton reagent, and photocatalytic reactions and biological methods include aerobic degradation, anaerobic degradation, biosorption, etc.

\section{Different Technologies Used for This Purpose}

2.1. Fenton Oxidation Process. Propelled oxidation strategies, for example, Fenton and altered Fenton forms are impressive to notice dye removal in textilewastewater. In Fenton process, low concentrations of $\mathrm{Fe}^{+2}$ and $\mathrm{H}_{2} \mathrm{O}_{2}$ arrangements are utilized, and these Fenton reagents create $\mathrm{OH}$ - radicals including high oxidation potential. The Fenton procedure, where nonlethal and innocuous reagents are applied at low concentrations, is extremely helpful for decolorization of wastewater since it is exceptionally viable and less dirty [23].

2.2. Membrane-Based Technologies. Conventional treatment methods experience the ill effects of a few loopholes. The utilization of film-based procedures in such cases can viably surmount a large portion of these disadvantages. The choice of suitable membrane relies upon the layer material which is thus administered by certain indispensable layer properties, for example, chemical, mechanical thermal and the film defenselessness to fouling; in addition, the layer pore size, which decides the substances that can be adequately held and layer shape, which demonstrates its capability to oppose stopping up are other significant parameters that must be thought about $[24,25]$. Microfiltration has constrained application in textile wastewater treatment due to its resemblence with filtration process. It is mainly used for removal of particlessuspension and colloidal dyes from exhausted dye bath and from discarded rinsing bath discharge; microfiltration membranes, however, permit the unconsumed auxiliary chemicals, dissolved organic pollutants and other soluble contaminants to escape with the permeate $[25,26]$. The ultrafiltration layer process has restricted applications in the textile business; this is mostly in light of the fact that the subatomic loads of the colors present in the exceptionally hued material release are a lot of lower than the subatomic weight cut-off (MWCO) of the ultrafiltration membranes [27]. Ultrafiltration (UF) is generally applied as a pretreatment step in frameworks requesting high level of procedure stream refinement; it is trailed by procedures, for example, nanofiltration (NF), or 


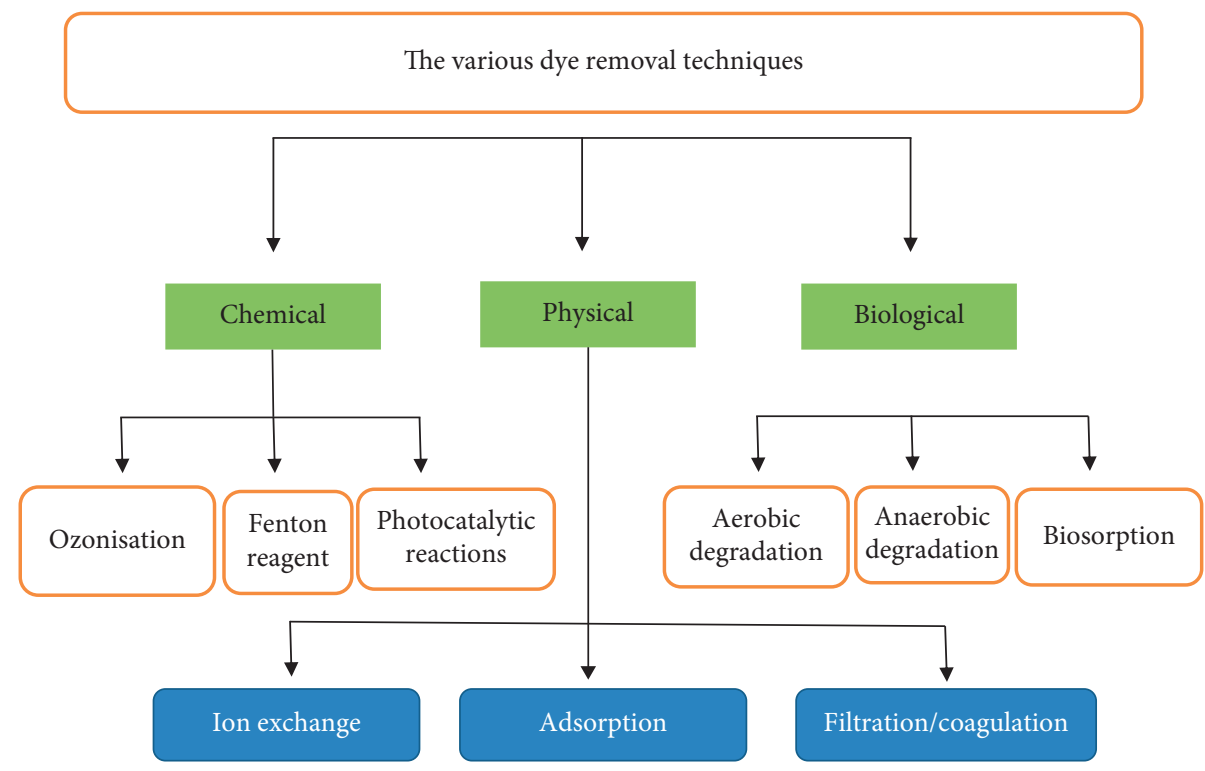

Figure 1: Classification of dye removal techniques. Techniques are classified as chemical, physical, and biological methods which are further classified into different techniques.

invert assimilation $(\mathrm{RO})$ stages, which fulfill the requests on process water quality [28]. Nanofiltration (NF) layer process is distinctively put between ultrafiltration and reverse osmosis, Its popularity over the years as an effective and simplified technology can be attributed to the benefits in terms of environmental pollution abatement, rejection, recovery and reuse of textile dyes, divalent salts and other auxiliary chemicals, recovery and reuse of brine . Furthermore, the generation of value pervade permits the reuse of treated wastewaters in significant procedures, for example, coloring and wrapping up [29].

2.3. Adsorption Technique. Adsorption methods have picked up support methodology among all the physicochemical techniques including adsorption, flocculation joined with flotation, membrane filtration, electromotor, coagulation, ozonation, oxidation, precipitation, and ion exchange [30,31]. Activated carbon is a generally utilized adsorbent in modern procedures, which is made out of a miniaturized scale permeable, homogenous structure with high surface territory and shows radiation security [32]. These days, there is an incredible enthusiasm for finding economical and powerful options in contrast to the current business activated carbon [33]. The most recent investigation shows the readiness of activated carbon from coconut husk with $\mathrm{H}_{2} \mathrm{SO}_{4}$ actuation (CSAC) and its capacity to evacuate textile colors (maxilon blue GRL and direct yellow DY 12) from fluid arrangements [34]. Agricultural wastes are inexhaustible, accessible in huge sums and more affordable when contrasted with different materials utilized as adsorbents. Agricultural squanders are superior to different adsorbents in light of the fact that the horticultural squanders are typically utilized without or with at least handling (washing, drying, and granulating) treatment[35]. There are explicit option farming by-products utilized strongly as color adsorbents, for example, nut structure, coir essence, and rice husk [36].

2.4. Microbial Biotechnology. Biotechnological methodologies have pulled in overall consideration for their relative cost viability and ecologically well-disposed nature. Most biotechnological approaches depend on the utilization of organisms that can possibly enzymatically debase and decolorize color containing fiber effluents. Azo dyes have been seen as decolorized prevalently under anaerobic conditions. Complete deterioration of azo dyes by microbial cells happens in two stages. In the initial step, drab metabolites are delivered by the reductive cleavage of the azo bond under anaerobic conditions. These metabolites are then disintegrated in a second step that requires oxidized conditions [37]. Enzymes, for example, azo reductases, laccases, lignin peroxidases, Mn peroxidases, DCIP-NADH reductases, tyrosinase, aminopyrine $\mathrm{N}$-demethylase, and riboflavin reductases, have been accounted for to be engaged with the breakdown of azo dyes [36, 38, 39].

2.5. Ozonation. Biotreated fabric wastewater can be more dangerous than the untreated discharge as certain colors are changed into little natural atoms; in this manner, further treatment is mostly required. Especially encouraging are the advance oxidation forms (AOPs); among the few AOP ozonation is the innovation that can be effectively executed in the previously existing treatment plants.operate[40, 41]. Utilization of ozonation as short posttreatment after a natural procedure can be gainful for the breakdown of refractory mixes and the evacuation of poisonous quality of material wastewater, yet observing of mutagenicity and harmfulness is a significant apparatus and ought to be utilized to supplement ordinary examination which centers around expulsion of supplements [42]. 
2.6. Phytoremediation. Phytoremediation really is the technique for treatment of contaminations by plants and their root related microflora [43]. Phytoremediation approach has been examined as a potential instrument to evacuate numerous risky natural contaminants like substantial metals, landfill leachates, pesticides, polyaromatic hydrocarbons, radionuclides, oil, unrefined petroleum, chlorinated solvents, polychlorinated biphenyls, explosives, weapons, and even the harmful gases [44]. Phytoremediation has advantages such as being a solar energy dependent and an aesthetically pleasant method of treatment. It offers a carbon neutral and thus environmental friendly approach for removal of toxic contaminants from the environment [45].

\section{Materials and Methods}

\subsection{Instruments}

3.1.1. $\mathrm{pH}$ Meter. $\mathrm{pH}$ meter is used for the measurement of acidity and alkalinity of solution. $\mathrm{pH}$ meter is used to measure the $\mathrm{pH}$ of wastewater at different time intervals during wastewater treatment process of industrial dye. This device is also considered as one of the easiest and devices used to measure $\mathrm{pH}$; in addition, this device is equipped with standard solutions to ensure the inspection process for accurate results.

3.1.2. UV-Visible Spectrophotometer. UV-visible spectrophotometer works on the absorption principle. It uses visible light as a source light. Different constituents absorb different wavelengths of visible light. Component concentration has a direct relation with the absorption of light.

Spectrophotometer was used to determine the concentration of dyes in wastewater at different time intervals during treatment process, and it can be explained by using a chart diagram.

3.1.3. Electrolytic Cell. Electrolytic cell is an undivided cell made of Perspex sheet in which degradation was carried out. Working electrode (anode) was made of copper and counter electrode (cathode) was made of aluminum plated iron. Both electrodes had dimensions of $15 \times 4 \mathrm{~cm}^{2}$ placed vertically at distance of $10 \mathrm{~cm}$ to each other.

3.1.4. Ultrasonic Bath. Ultrasonic bath as shown in Figure 2 produces high energy sound waves. The frequency of these waves ranges from $10-400 \mathrm{kHz}$. These sound waves help in wastewater treatment as they transfer their energy to pollutant molecule. Due to their high energy, the pollutant molecule ruptured.

3.1.5. Sonoelectrolytic Reactor (SER). It is the combination of two units, i.e., an electrolytic cell and ultrasonic bath. The electrolytic cell was placed in the ultrasonic bath, and both are operated simultaneously for wastewater treatment as explained in Figure 2.

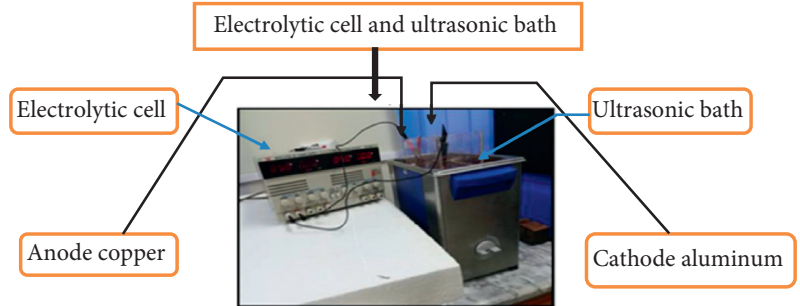

Figure 2: Sonoelectrolytic reactor. It is a combination of electrolytic cell and ultrasonic bath.

\section{Experimentation}

The wastewater was treated with two systems. The experimentation of our study consists of three steps:

(1) Sonoelectrolytic reactor.

(2) Adsorbent use.

(3) Trickling filter.

\subsection{Treatment through Sonoelectrolytic Reactor (SER)}

4.1.1. Experiment No. 1. $50 \mathrm{ppm}$ concentration of solution of dye colored red was prepared. The volume of solution was $2 \mathrm{~L}$. The underlying $\mathrm{pH}$, temperature, and absorbance were noted, and the arrangement was placed in sonoelectrolytic reactor. The treatment process continued for 210 minutes. The time interval was 30 minutes. Different parameters like absorbance, $\mathrm{pH}$, and temperature were determined after every $30 \mathrm{~min}$ of interval.

4.1.2. Experiment No. 2 (Acidic Solution). $50 \mathrm{ppm}$ concentration of red dye solution was prepared. One milliliter for each liter of concentrated $\mathrm{HCl}$ was incorporated to solution. Solution's color was changed from red to blue. The absorbance was now measured at wavelength of $570 \mathrm{~nm}$. The volume of solution was $2 \mathrm{~L}$. The initial $\mathrm{pH}$, temperature, and absorbance were noted, and same procedure is repeated as discussed earlier.

4.1.3. Experiment No. 3 (Basic Solution). $50 \mathrm{ppm}$ concentration of red dye solution was prepared. $0.1 \mathrm{~N}$ solution $\mathrm{NaOH}$ was added to solution. The absorbance was measured at wavelength of $495 \mathrm{~nm}$. The volume of solution was $2 \mathrm{~L}$. The initial $\mathrm{pH}$, temperature, and absorbance were noted, and same procedure is repeated as discussed earlier.

4.1.4. Experiment No. 4 (Acid and Base). $50 \mathrm{ppm}$ concentration of red dye solution was prepared. $0.1 \mathrm{~N}$ solution of $\mathrm{NaOH}$ and $1 \mathrm{ml} /$ liter of concentrated $\mathrm{HCl}$ was added to solution. Agglomerate was formed in the solution. The solution was set for settling. No treatment was done.

4.1.5. Experiment No. 5 (Collected Sample). The sample was collected from cloth dyeing factory. The maximum absorbance that was measured by spectrophotometer was $675 \mathrm{~nm}$. The volume of solution was $1 \mathrm{~L}$. The initial $\mathrm{pH}$, temperature, 
and absorbance were noted, and same procedure is repeated as discussed earlier.

\subsection{Treatment through Adsorbent}

4.2.1. Adsorbent. The adsorbent used was sugarcane bagasse. The sugarcane leftover was collected from sugarcane juice shop and then dried in sunlight and ground into small size.

4.3. Bio-Trickling Filter (TF). The bagasse adsorbent was used in the trickling filter. The laboratory scale trickling filter was constructed as shown in Figure 3. The volume of trickling filter was 4 liters. The filter media used were gravels and adsorbent layer. The filter depth was $8 \mathrm{~cm}$. The bottom layer of filter was of gravels of $10 \mathrm{~mm}$; this layer was of $5 \mathrm{~cm}$. The second layer of $3 \mathrm{~cm}$ was laid of gravels having size of $2 \mathrm{~mm}$. The upper layer of adsorbent was thin, approximately $2 \mathrm{~mm}$. The quantity of adsorbent used was $24 \mathrm{gm}$. Two tests were performed on trickling filter.

4.3.1. Experiment No. 1. $50 \mathrm{ppm}$ concentration of solution of dye colored red was prepared. Volume of suspension was $4 \mathrm{~L}$. The initial $\mathrm{pH}$, temperature, and absorbance were noted, and same procedure is repeated as discussed earlier.

4.3.2. Experiment No. 2 (Collected Sample). The sample was collected from cloth dyeing shop. The maximum absorbance that was measured by spectrophotometer was $675 \mathrm{~nm}$. The volume of solution was $4 \mathrm{~L}$. The initial $\mathrm{pH}$, temperature, and absorbance were noted, and same procedure is repeated as discussed earlier.

\section{Results and Discussion}

\subsection{Treatment through Sonoelectrochemical Reactor}

5.1.1. Experiment No. 1. Results shown in Table 1 are explained with the help of graphs (Figure 4(a)-4(c)). Table 1 shows the experiment implementation time and specified 210 minutes, where 8 samples were taken during different time every 30 minutes; the results showed (Figures 4(a)$4(c))$ a decrease in the absorbance from 1.637 to 0.413 with an increase in the efficiency from $12.6 \%$ up to $99.3 \%$ at 210 minutes and equivalent $\mathrm{pH}$ values, which means that the processing time is 3.5 hours.

Test continued for 210 minutes and 60 minutes settling was given as shown in Table 1. reactor. The $\mathrm{pH}$ also changes during treatment process. The max temperature reaches $61.5^{\circ} \mathrm{C}$ due to dye degradation because sound waves are highly energetic when they strike with atoms; the atoms are split into small particles which settle down during settling. Similarly, during electrolysis, movement of electrons also degrades dye atoms and emits energy due to this temperature increase. The efficiency was $99.3 \%$ after filtration as shown in Table 1.

5.1.2. Experiment No. 2 (Acidic Solution). Table 2 shows the experiment implementation time and specified 90 minutes,

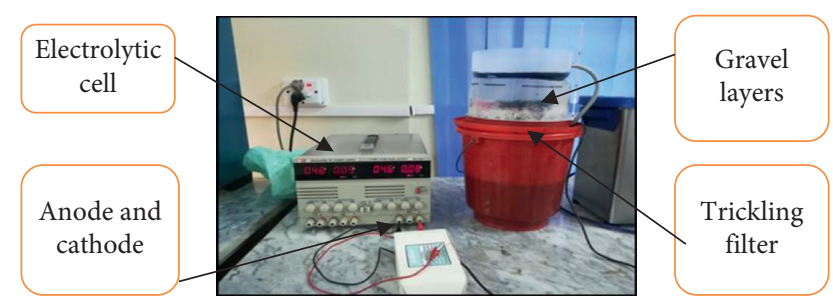

FIGURE 3: Trickling filter. It consists of gravels layer, electrolytic cell, and anode and cathode.

where 4 samples were taken during different time every 30 minutes; the results showed (Figure $5(\mathrm{a})-5(\mathrm{c})$ ) a decrease in the absorbance from 1.154 to 0.059 with an increase in the efficiency from $13.7 \%$ up to $94.9 \%$ at 90 minutes, which means that the processing time is 1.5 hours.

Test continued for 90 minutes and 60 minutes ettling time was provided.reactorDecrease in absorbance with time depicts the degradation of dye in solution within the reactor. The $\mathrm{pH}$ also changes during treatment process. The max temperature reaches $51^{\circ} \mathrm{C}$. The efficiency was $94.9 \%$ after filtration.

5.1.3. Experiment No. 3 (Basic Solution). Table 3 shows the experiment implementation time and specified 210 minutes, where 4 samples were taken during different time every 30 minutes; the results showed (Figures 6(a)-6(c)) a decrease in the absorbance from 1.548 to 0.074 with an increase in the efficiency from $47.9 \%$ up to $95.2 \%$ at 210 minutes and high $\mathrm{pH}$ values, which means that the processing time is 1.5 hours.

Test continued for 90 minutes and 60 minutes settling was provided. reactorDecrease in absorbance with time depicts the degradation of dye in solution within the reactor. The $\mathrm{pH}$ also changes during treatment process. The max temperature reaches $52^{\circ} \mathrm{C}$. The efficiency was $95.22 \%$ after filtration.

5.1.4. Experiment No. 4 (Collected Sample). Table 4 shows the experiment implementation time and specified 210 minutes, where 4 samples were taken during different time every 30 minutes; the results showed (Figures $7(a)-7(c)$ ) a decrease in the absorbance from 3.824 to 0.138 with an increase in the efficiency from $1.15 \%$ up to $96.4 \%$ at 210 minutes, which means that the processing time is 1.5 hours.

Test continued for 90 minutes and 60 minutes settling time was provided.reactorDecrease in absorbance with time depicts the degradation of dye in solution within the reactor. The $\mathrm{pH}$ also changes during treatment process. The max temperature reaches $59^{\circ} \mathrm{C}$. The efficiency was $96.4 \%$ after filtration.

Figure 8 shows the initial and final absorbance of wastewater. This shows that SER is a preferable treatment process in short time period.

5.2. Drawbacks of Sonoelectrochemical Reactor. The treatment efficiency of sonoelectrolytic reactor was very good. 
TABle 1: Different characteristic values of red dye in the absence of acid and base.

\begin{tabular}{lccccc}
\hline Time $(\mathrm{min})$ & Absorbance $(675 \mathrm{~nm})$ & $\mathrm{pH}$ & Concentration $(\mathrm{ppm})$ & Removal $(\%)$ & Temperature $\left({ }^{\circ} \mathrm{C}\right)$ \\
\hline 0 & 1.637 & 7.38 & 50 & 0 & 25 \\
30 & 1.43 & 7.19 & 43.68 & 32.6 & 4.5 \\
60 & 1.072 & 6.9 & 32.74 & 38.7 & 47 \\
90 & 1.003 & 6.39 & 30.64 & 44.6 & 51 \\
120 & 0.907 & 6.43 & 27.7 & 56.6 & 56 \\
150 & 0.891 & 6.91 & 27.21 & 74.8 & 58 \\
180 & 0.709 & 7.35 & 21.66 & 94.4 & 61.2 \\
210 & 0.413 & 7.4 & 12.61 & 99.3 & 25 \\
Settling (60 minutes) & 0.091 & 6.23 & 2.779 & 0.367 & 25 \\
Filtration & 0.012 & 6.45 & & & \\
\hline
\end{tabular}

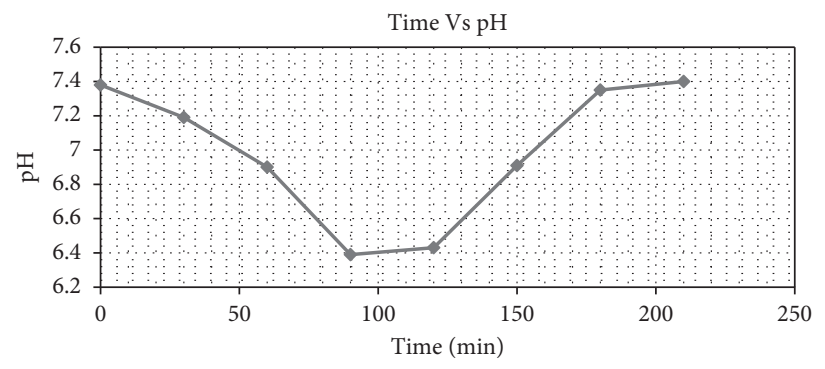

(a)

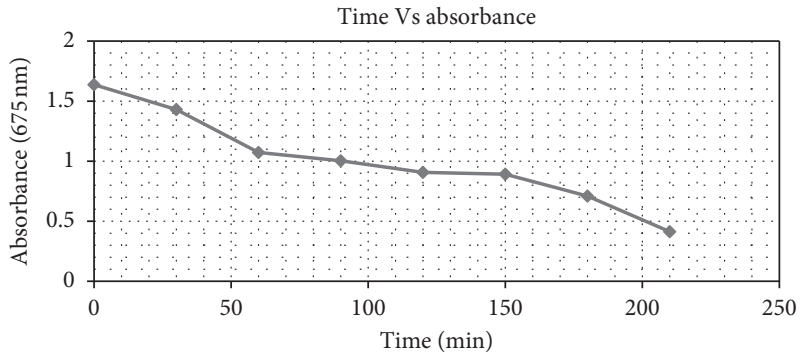

(b)

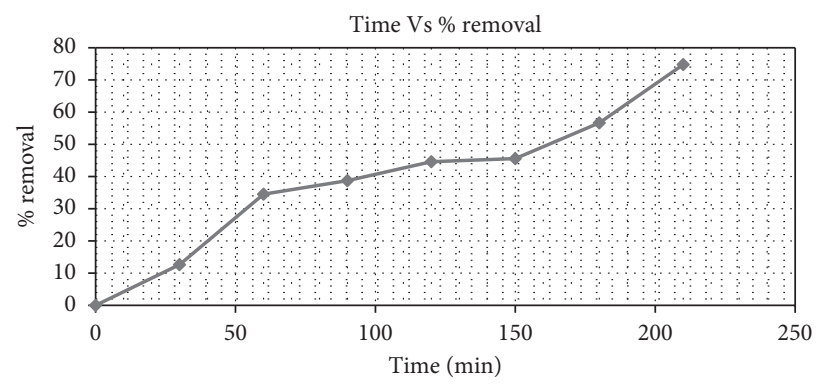

(c)

Figure 4: (a) Plot of $\mathrm{pH}$ with respect to time over 250 min period. (b) Plot of absorbance with respect to time over 250 min period. (c) Plot of percent removal with respect to time over 250 min period.

TABLE 2: Different characteristic values of red dye in acidic solution.

\begin{tabular}{lccccc}
\hline Time $(\mathrm{min})$ & Absorbance $(675 \mathrm{~nm})$ & $\mathrm{pH}$ & Concentration $(\mathrm{ppm})$ & Removal $(\%)$ & Temperature $\left({ }^{\circ} \mathrm{C}\right)$ \\
\hline 0 & 1.154 & 2.38 & 50 & 0 & 25 \\
30 & 0.996 & 2.18 & 43.2 & 64.2 & 42 \\
60 & 0.413 & 2.15 & 17.9 & 73.3 & 45 \\
90 & 0.308 & 2.45 & 13.3 & 91.2 & 51 \\
Settling (60 minutes) & 0.101 & 4.85 & 4.38 & 94.9 & 25 \\
Filtration & 0.059 & 5.02 & 2.56 & 25 \\
\hline
\end{tabular}

The only drawback assessed was deposition of dyes on electrodes during the treatment process that needs cleaning after every test. This depends upon the concentration of dyes in wastewater; higher concentration leads toward more deposition on electrodes. Another problem which may occur was sludge formation. High amount of sludge is produced in this process that is difficult to handle.

\subsection{Treatment through Bio-Trickling Filter (TF)}

5.3.1. Experiment No. 1. Table 5 shows the experiment implementation time and specified 110 minutes, where 4 samples were taken during different time every 30 minutes; the results showed (Figures 9(a)-9(c)) a decrease in the absorbance from 1.591 to 0.067 with an increase in the 


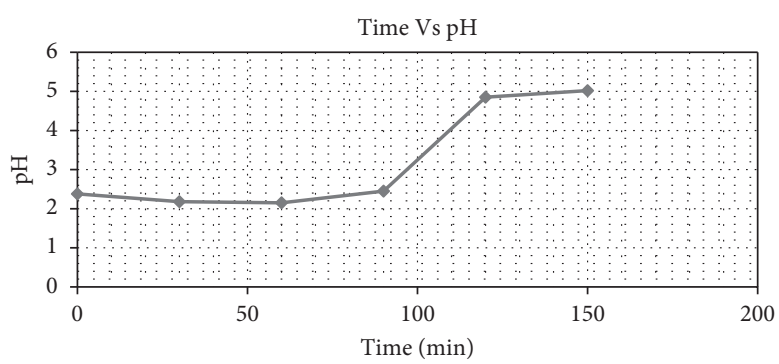

(a)

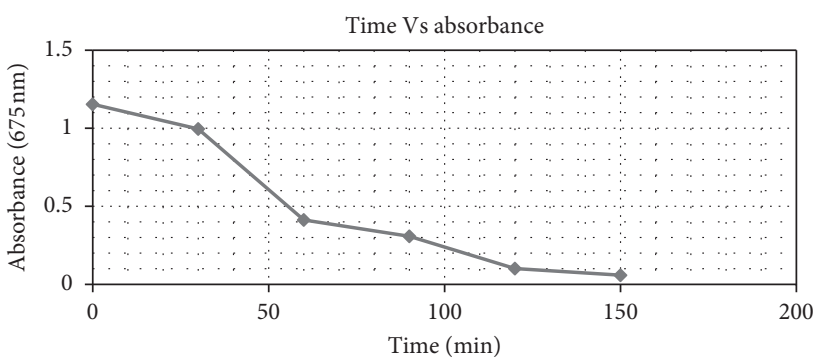

(b)

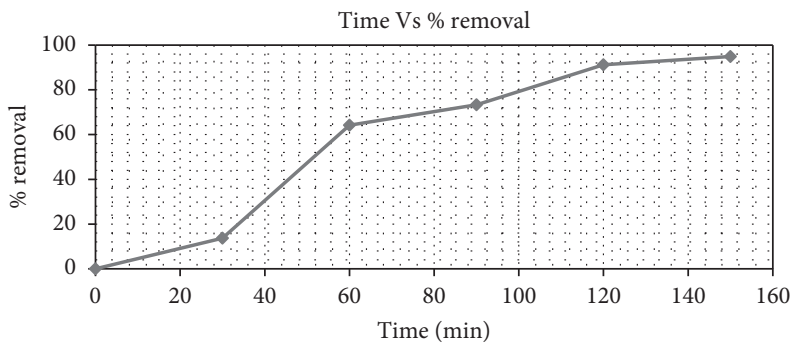

(c)

Figure 5: (a) Plot of $\mathrm{pH}$ with respect to time over 200 min period. (b) Plot of absorbance with respect to time over $200 \mathrm{~min}$ period. (c) Plot of percent removal with respect to time over $160 \mathrm{~min}$ period.

TABLE 3: Different characteristic values of red dye in basic solution.

\begin{tabular}{lccccc}
\hline Time $(\mathrm{min})$ & Absorbance $(675 \mathrm{~nm})$ & $\mathrm{pH}$ & Concentration $(\mathrm{ppm})$ & Removal $(\%)$ & Temperature $\left({ }^{\circ} \mathrm{C}\right)$ \\
\hline 0 & 1.548 & 11.95 & 50 & 0 & 25 \\
30 & 0.806 & 12.17 & 26 & 66.93 & 41 \\
60 & 0.514 & 12.3 & 16.6 & 65.18 & 45 \\
90 & 0.539 & 12.22 & 17.4 & 91.34 & 52 \\
Settling (60 minutes) & 0.134 & 12.22 & 4.33 & 95.22 & 25 \\
Filtration & 0.074 & 12.05 & 2.39 & 25 \\
\hline
\end{tabular}

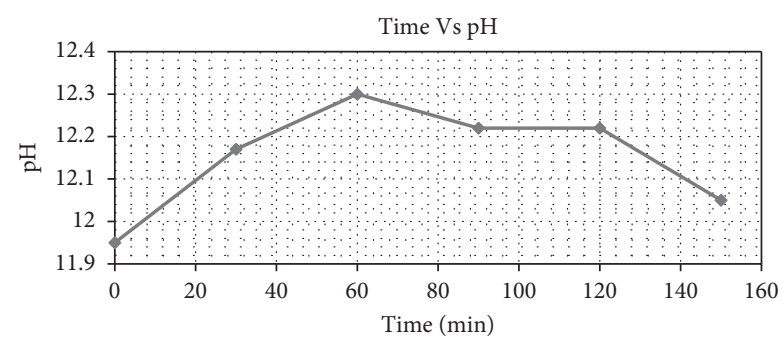

(a)

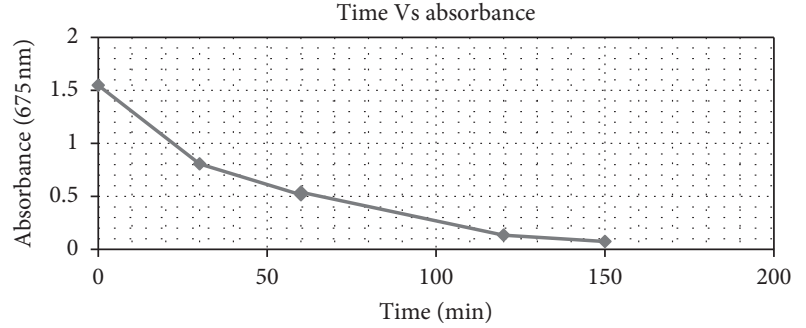

(b)

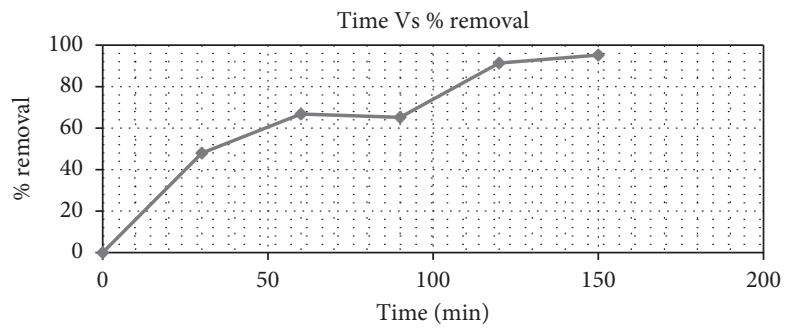

(c)

Figure 6: (a) Plot of $\mathrm{pH}$ with respect to time over 160 min period. (b) Plot of absorbance with respect to time over 200 min period. (c) Plot of percent removal with respect to time over $200 \mathrm{~min}$ period. 
TABLE 4: Different characteristic values of collected sample.

\begin{tabular}{lcccc}
\hline Time $(\mathrm{min})$ & Absorbance $(675 \mathrm{~nm})$ & $\mathrm{pH}$ & Removal $(\%)$ & Temperature $\left({ }^{\circ} \mathrm{C}\right)$ \\
\hline 0 & 3.824 & 8.53 & 0 & 25 \\
30 & 3.78 & 8.97 & 1.15 & 47 \\
60 & 2.23 & 9.36 & 41.7 & 55 \\
90 & 1.9 & 10.09 & 50.3 & 59 \\
Settling (60 minutes) & 1.28 & 9.83 & 66.5 & 25 \\
Filtration & 0.138 & 8.9 & 96.4 & 25 \\
\hline
\end{tabular}

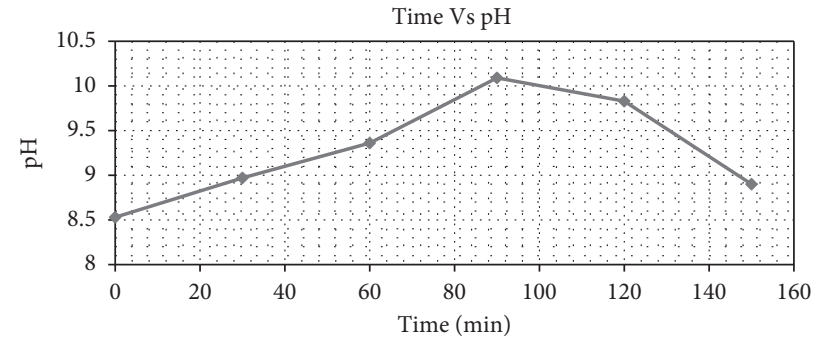

(a)

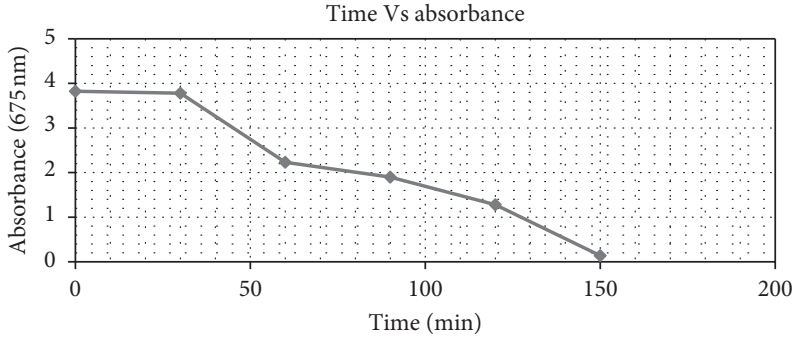

(b)

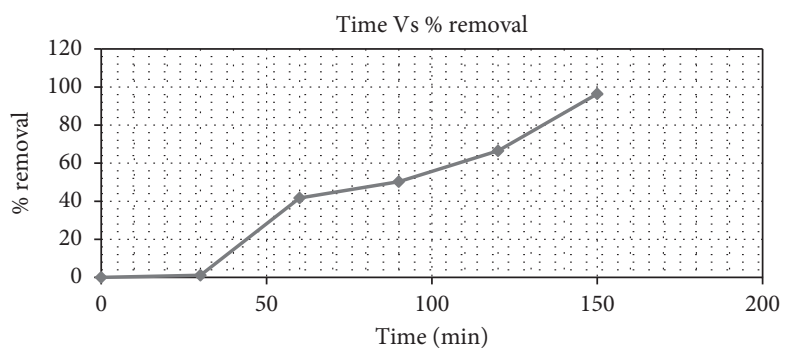

(c)

Figure 7: (a) Plot of $\mathrm{pH}$ with respect to time over 160 min period. (b) Plot of absorbance with respect to time over 200 min period. (c) Plot of percent removal with respect to time over $200 \mathrm{~min}$ period.

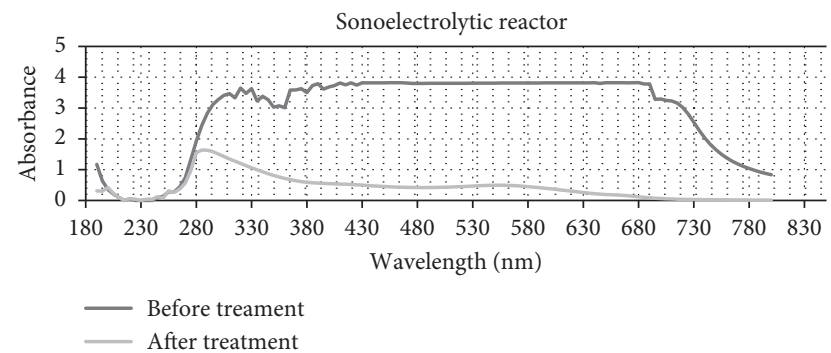

Figure 8: Plot of absorbance with respect to wavelength over $830 \mathrm{~nm}$. It shows a change in parameters of wastewater (before and after treatment).

efficiency from $83.47 \%$ up to $95.78 \%$ at 110 minutes and equivalent $\mathrm{pH}$ values, which means that the processing time is 1.5 hours.

Test continued for 110 minutes. reactorDecrease in absorbance with time depicts the degradation of dye in solution within the reactor. The $\mathrm{pH}$ also changes during treatment process. The efficiency was $95.8 \%$.
5.3.2. Experiment No. 2 (Collected Sample). Table 6 shows the experiment implementation time and specified 240 minutes, where 9 samples were taken during different time every 30 minutes; the results showed (Figures 10(a)-10(c)) a decrease in the absorbance from 3.79 to 2.02 with an increase in the efficiency from $20.95 \%$ up to $46.7 \%$ at 240 minutes and equivalent $\mathrm{pH}$ values, which means that the processing time is 4 hours.

Test continued for 110 minutes. reactorDecrease in absorbance with time depicts the degradation of dye in solution within the reactor. The $\mathrm{pH}$ also changes during treatment process. The efficiency was $46.7 \%$.

The graph in Figure 11 shows the initial and final absorbance of wastewater. This shows that TF is not a good treatment process in short time period. Also the graph shows abrupt variation causing an increase in absorbance value as reaction stopped and particles deposited instead of settling deposited. The problem can be removed using filter paper.

5.4. Drawbacks of Bio-Trickling Filter. Treatment in biotrickling filter is a time-consuming process as both the 
TABLE 5: Different characteristic values as a result of dye treatment through biofilter.

\begin{tabular}{lcccc}
\hline Time $(\mathrm{min})$ & Absorbance $(495 \mathrm{~nm})$ & $\mathrm{pH}$ & Concentration $(\mathrm{ppm})$ & Removal $(\%)$ \\
\hline 0 & 1.591 & 6.33 & 50 & 0 \\
30 & 0.263 & 7.53 & 8.27 & 83.47 \\
90 & 0.069 & 7.7 & 2.17 & 95.663 \\
110 & 0.067 & 7.66 & 2.11 & 95.789 \\
\hline
\end{tabular}

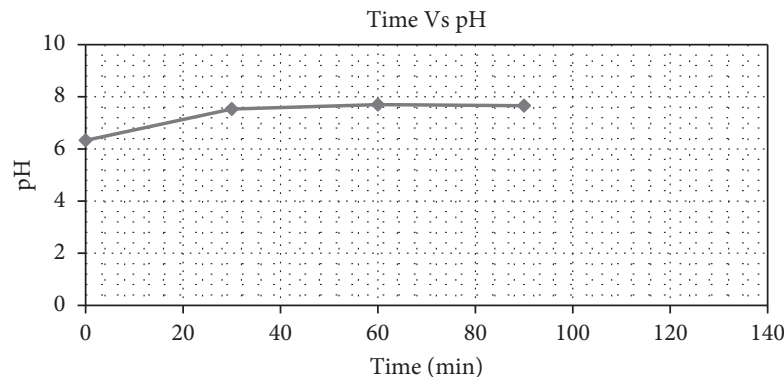

(a)

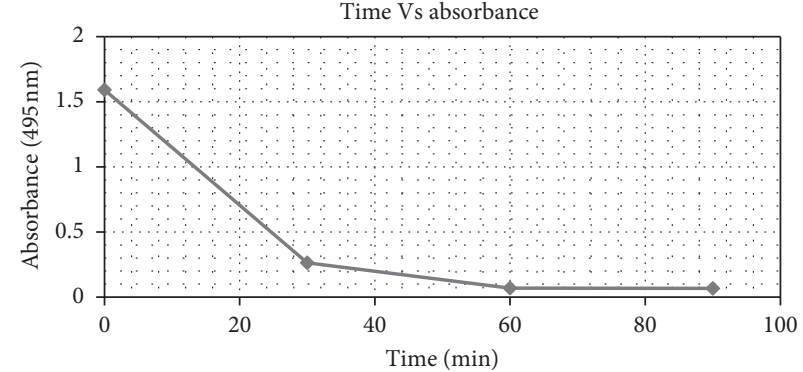

(b)

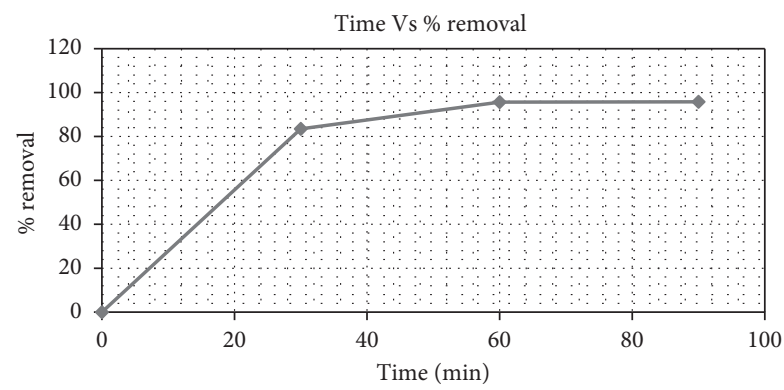

(c)

Figure 9: (a) Plot of $\mathrm{pH}$ with respect to time over 140 min period. (b) Plot of absorbance with respect to time over 100 min period. (c) Plot of percent removal with respect to time over $100 \mathrm{~min}$ period.

TABLE 6: Different characteristic values of collected sample treatment through biofilter.

\begin{tabular}{lccc}
\hline Time $(\mathrm{min})$ & Absorbance $(495 \mathrm{~nm})$ & $\mathrm{pH}$ & Removal $(\%)$ \\
\hline 0 & 3.79 & 7.38 & 0 \\
60 & 2.966 & 7.74 & 20.95 \\
120 & 2.413 & 7.75 & 36.332 \\
180 & 2.182 & 7.73 & 42.427 \\
240 & 2.02 & 7.6 & 46.702 \\
\hline
\end{tabular}

biological treatment and the physical treatment are required. Biofilm generation is a time requisite process, and the other issue was the capacity of adsorbent. The adsorbent capacity decreases with time, and when adsorbent surface area is utilized thoroughly, there is a need to replace the old adsorbent with the new one.

5.5. Comparative Analysis of Both Treatment Systems. Table 7 shows the comparative analysis of treatment systems by sonoelectrolytic reactor and trickling filter.

5.6. Efficiency Comparison of Both Treatment Systems. Figure 12 shows the relevance between treatment efficiencies and time. It shows that sonoelectrolytic reactor (SER) took less time to treat textile wastewater as compared to trickling filter.

5.7. Effect of Temperature. Figures 13(a) and 13(b) show the temperature variation with respect to time for different experimental setup used in the ultrasound-assisted electrochemical reactor (UAER) method. It is observed that temperature increases as the experiment progresses. The absorbance decreases with increase of temperature, ultimately causing dye degradation to increase, respectively. The maximum temperature noted in UAER method is $56^{\circ} \mathrm{C}$.

Figure 13(b) shows the temperature variation for different experimental setup used in the sonoelectrochemical reactor (SER) method. The temperature shows the similar effect as observed in UEAR graph values. The maximum temperature noted in the SER method is $59^{\circ} \mathrm{C}$. After 90 minutes, the experiment stops and the aqueous solution is kept for settling for 60 minutes, causing an abrupt decrease of temperature. Also, it is noted in both UEAR and SER methods that the rate of decolonization reduces after temperature reaches $50^{\circ} \mathrm{C}$ and rate of increase of temperature also decreases after 150 minutes in both the aforementioned techniques. 


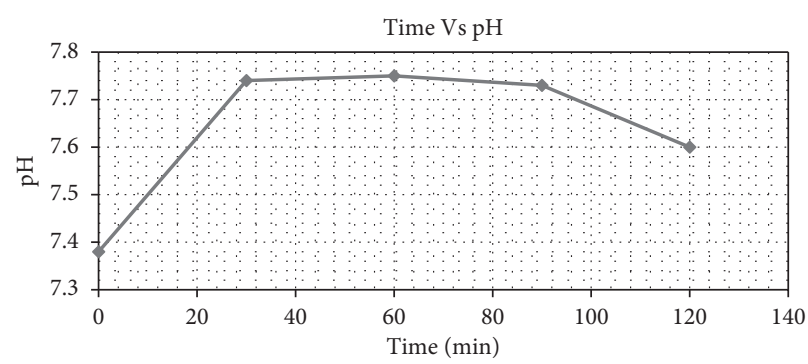

(a)

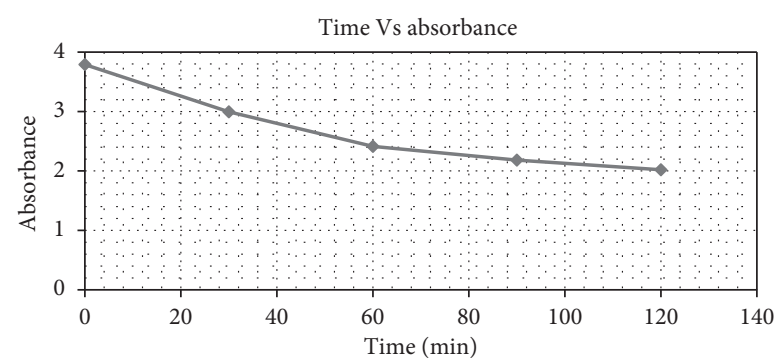

(b)

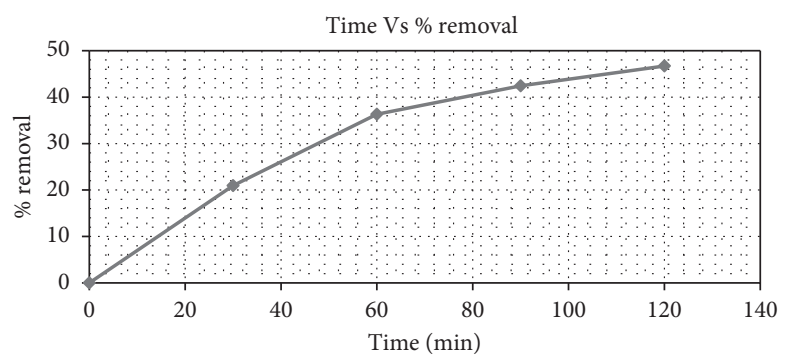

(c)

Figure 10: (a) Plot of $\mathrm{pH}$ with respect to time over 140 min period. (b) Plot of absorbance with respect to time over 140 min period. (c) Plot of percent removal with respect to time over $140 \mathrm{~min}$ period.

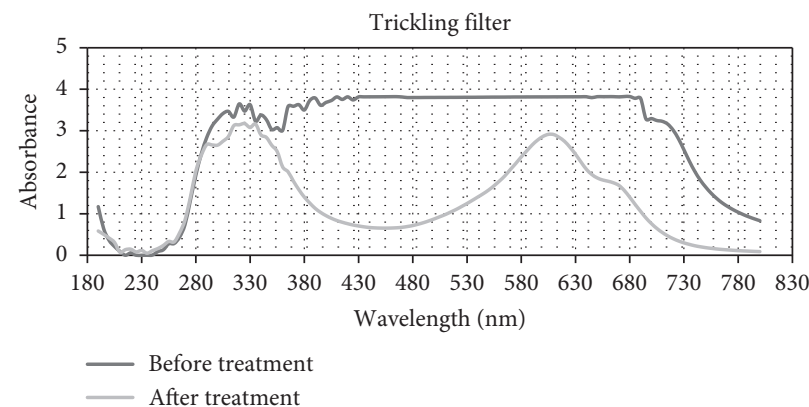

FIGURE 11: Plot of absorbance with respect to wavelength over $830 \mathrm{~nm}$. It shows the treatment efficiency of trickling filter.

TABLe 7: Comparative analysis of treatment systems.

\begin{tabular}{lc}
\hline Sonoelectrolytic reactor & Trickling filter \\
\hline Fast treatment process & Slow treatment process \\
Increased copper concentration in effluent & No increase in copper concentration in effluent \\
Deposition on electrodes & Adsorbent capacity decreases with process \\
More efficiency w.r.t time & Less efficient w.r.t time \\
\hline
\end{tabular}

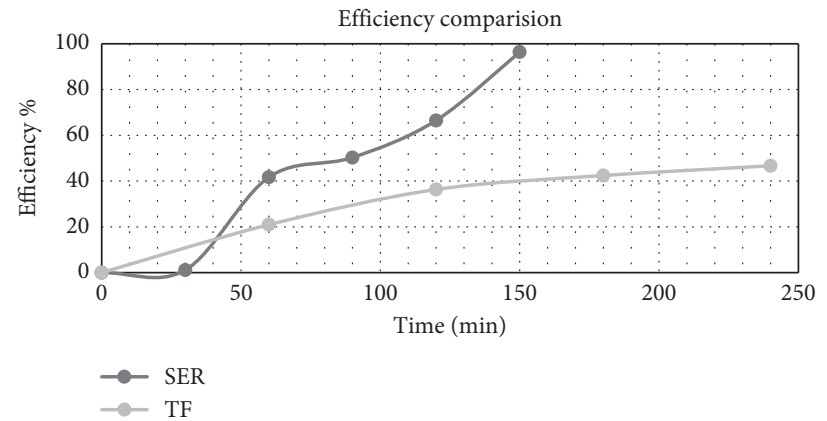

FIGURE 12: Plot of efficiency with respect to time over 250 min period. It shows the efficiency comparison of SER and TF. 


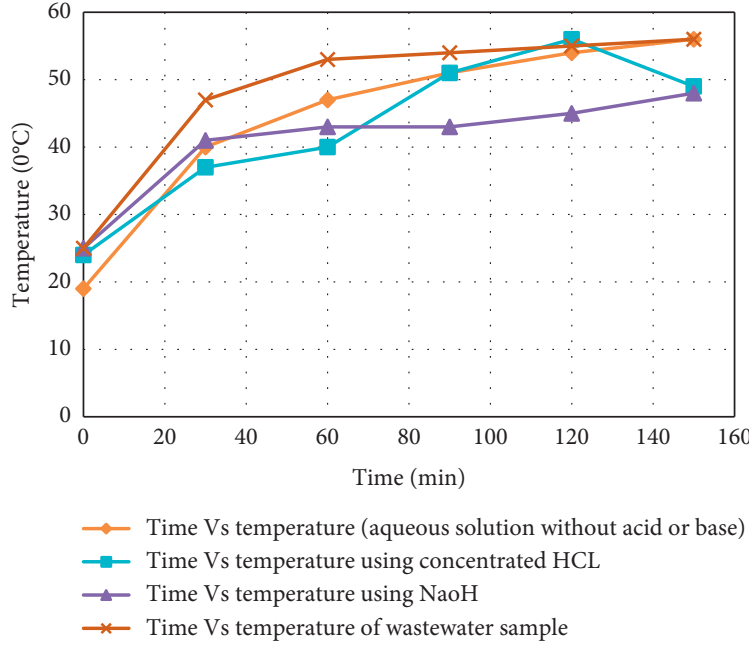

(a)

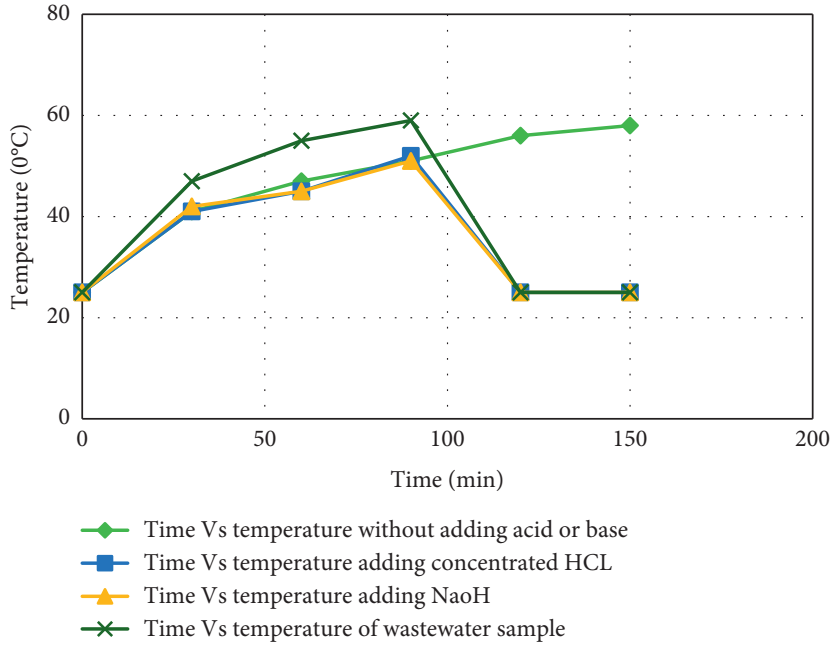

(b)

FIgURE 13: (a) Temperature variation graph with respect to time using the UEAR method. (b) Temperature variation graph with respect to time using the SER method.

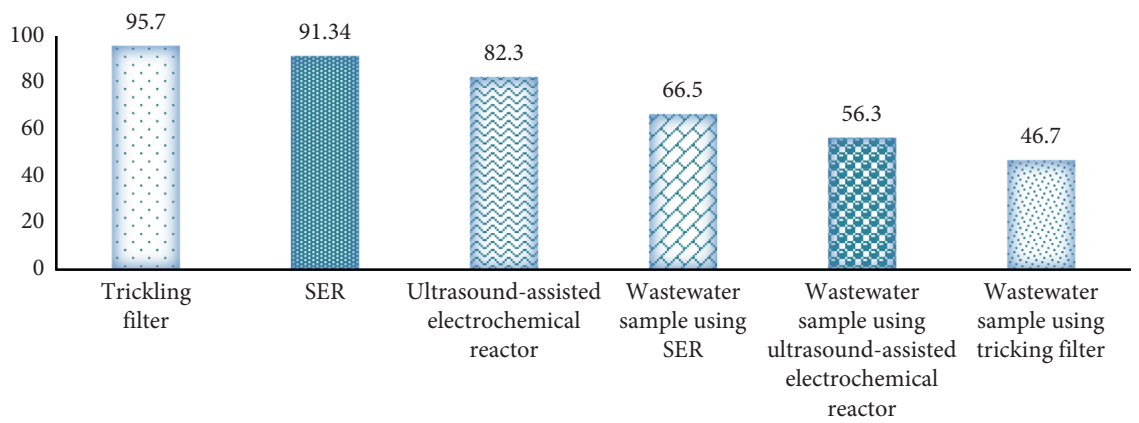

FIgURE 14: Comparison based on efficiency. Dye removal percentage using different techniques.

Figure 14 shows the comparison between trickling filter, sonoelectrolytic reactor, and ultrasound-assisted electrochemical reactor based on their degradation efficiency.

\section{Conclusion}

Fabric discharge can cause drain, ulceration of skin, sickness, skin bothering, and dermatitis. Excessive quantity of harmful synthetic substances in the wastewater inhibits sunlight and enhances biological oxygen demand, thereby hindering photosynthesis and reoxygenation process. Hence, the need to treat such an effluent is urgent.

In this study, performances of sonoelectrolytic and biological processes to remove color and organic compounds from fabric discharge were investigated and compared. After performing a series of experiments on dye solution, it was easy to conclude that efficiency of degradation of dyes can be enhanced by changing the parameters like $\mathrm{pH}$, temperature, and types of chemicals used. Conclusions derived from the experimental results shows that the treatment through SER is faster than trickling filter because in TF the adsorbent capacity decreases with time and is a time-consuming process, but the chance of deposition on electrodes also increases in SER so both these processes can yield better results if these problems are eliminated.

\section{Data Availability}

The data used to support the findings of the study are available from the corresponding author upon request.

\section{Conflicts of Interest}

The authors declare that they have no conflicts of interest.

\section{Acknowledgments}

Engr. Basem Mohammed Al-Sakkaf acknowledges the technical and moral support provided by the University of Engineering and Technology, Taxila, 47050, Pakistan. The authors are really thankful to Higher Education Commission Pakistan (HEC) for providing them financial support through the National Research Program for Universities (NRPU) (project no. 10570). Authors are also thankful to Mr. Baqar Ali Siddique, a student of Environmental Engineering Department, for his help in research. 


\section{References}

[1] S. Rajoriya, S. Bargole, S. George, and V. K. Saharan, "Treatment of textile dyeing industry effluent using hydrodynamic cavitation in combination with advanced oxidation reagents," Journal of Hazardous Materials, vol. 344, pp. 1109-1115, 2018.

[2] D. A. Yaseen and M. Scholz, "Textile dye wastewater characteristics and constituents of synthetic effluents: a critical review," International Journal of Environmental Science and Technology, vol. 16, no. 2, pp. 1193-1226, 2019.

[3] A. Pirkarami and M. E. Olya, "Removal of dye from industrial wastewater with an emphasis on improving economic efficiency and degradation mechanism," Journal of Saudi Chemical Society, vol. 21, pp. S179-S186, 2017.

[4] F. Ntuli, "Characterization of effluent from textile wet finishing operations," in Proceedings of the World Congress on Engineering and Computer Science., 2009, London, UK, July 2009.

[5] S. Imtiazuddin, M. Mumtaz, and K. A. Mallick, "Pollutants of wastewater characteristics in textile industries," Journal of Basic and Applied Sciences, vol. 8, pp. 554-556, 2012.

[6] X. Lu, L. Liu, R. Liu, and J. Chen, "Textile wastewater reuse as an alternative water source for dyeing and finishing processes: a case study," Desalination, vol. 258, no. 1-3, pp. 229-232, 2010.

[7] S. Popli and U. D. Patel, "Destruction of azo dyes by anaerobic-aerobic sequential biological treatment: a review," International Journal of Environmental Science and Technology, vol. 12, no. 1, pp. 405-420, 2015.

[8] V. M. Correia, T. Stephenson, and S. J. Judd, "Characterisation of textile wastewaters-a review," Environmental Technology, vol. 15, no. 10, pp. 917-929, 1994.

[9] D. S. Babu, V. Srivastava, P. V. Nidheesh, and M. S. Kumar, "Detoxification of water and wastewater by advanced oxidation processes," Science of the Total Environment, vol. 696, p. 133961, 2019.

[10] R. Javaid and U. Y. Qazi, "Catalytic oxidation process for the degradation of synthetic dyes: an overview," International Journal of Environmental Research and Public Health, vol. 16, no. 11, p. 2066, 2019.

[11] J. Madhavan, J. Theerthagiri, D. Balaji, S. Sunitha, Choi, and M. Ashokkumar, "Hybrid advanced oxidation processes involving ultrasound: an overview," Molecules, vol. 24, no. 18, p. 3341, 2019.

[12] A. B. Dos Santos, F. J. Cervantes, and J. B. Van Lier, "Review paper on current technologies for decolourisation of textile wastewaters: perspectives for anaerobic biotechnology," Bioresource Technology, vol. 98, no. 12, pp. 2369-2385, 2007.

[13] F. M. D. Chequer, T. M. Lizier, R. de Felício et al., "Analyses of the genotoxic and mutagenic potential of the products formed after the biotransformation of the azo dye Disperse Red 1," Toxicology in Vitro, vol. 25, no. 8, pp. 2054-2063, 2011.

[14] R. O. A. de Lima, A. P. Bazo, D. M. F. Salvadori, C. M. Rech, D. d. P. Oliveira, and G. d. A. Umbuzeiro, "Mutagenic and carcinogenic potential of a textile azo dye processing plant effluent that impacts a drinking water source," Mutation Research/Genetic Toxicology and Environmental Mutagenesis, vol. 626, no. 1-2, pp. 53-60, 2007.

[15] C. Zaharia, D. Suteu, A. Muresan, R. Muresan, and A. Popescu, "Textile wastewater treatment by homogeneous oxidation with hydrogen peroxide," Environmental Engineering and Management Journal, vol. 8, no. 6, pp. 1359-1369, 2009.
[16] E. C. Lima, B. Royer, J. C. P. Vaghetti et al., "Application of Brazilian pine-fruit shell as a biosorbent to removal of reactive red 194 textile dye from aqueous solution," Journal of Hazardous Materials, vol. 155, no. 3, pp. 536-550, 2008.

[17] B. Royer et al., "Applications of Brazilian pine-fruit shell in natural and carbonized forms as adsorbents to removal of methylene blue from aqueous solutions-kinetic and equilibrium study," Journal of Hazardous Materials, vol. 164, no. 2-3, pp. 1213-1222, 2009.

[18] A. Sakalis, K. Fytianos, U. Nickel, and A. Voulgaropoulos, “A comparative study of platinised titanium and niobe/synthetic diamond as anodes in the electrochemical treatment of textile wastewater," Chemical Engineering Journal, vol. 119, no. 2-3, pp. 127-133, 2006.

[19] A. Gürses, "Dyes and pigments: their structure and properties," in Dyes and Pigments, pp. 13-29, Springer, Berlin, Germany, 2016.

[20] V. Golob, A. Vinder, and M. Simonic, "Efficiency of the coagulation/flocculation method for the treatment of dyebath effluents," Dyes and Pigments, vol. 67, no. 2, pp. 93-97, 2005.

[21] G. Crini and E. Lichtfouse, "Advantages and disadvantages of techniques used for wastewater treatment," Environmental Chemistry Letters, vol. 17, no. 1, pp. 145-155, 2019.

[22] K. G. Pavithra, P. Senthil Kumar, V. Jaikumar, and P. Sundar Rajan, "Removal of colorants from wastewater: a review on sources and treatment strategies," Journal of Industrial and Engineering Chemistry, vol. 75, pp. 1-19, 2019.

[23] K. Lacasse and W. Baumann, "Environmental considerations for textile processes and chemicals," in Textile Chemicals, pp. 484-647, Springer, Berlin, Germany, 2004.

[24] A. B. Koltuniewicz and E. Drioli, "Membranes in clean technologies," Membranes, vol. 31, pp. 3-1, 2008.

[25] J. Dasgupta, J. Sikder, S. Chakraborty, S. Curcio, and E. Drioli, "Remediation of textile effluents by membrane based treatment techniques: a state of the art review," Journal of Environmental Management, vol. 147, pp. 55-72, 2015.

[26] Y. Juang, E. Nurhayati, C. Huang, J. R. Pan, and S. Huang, "A hybrid electrochemical advanced oxidation/microfiltration system using $\mathrm{BDD} / \mathrm{Ti}$ anode for acid yellow 36 dye wastewater treatment," Separation and Purification Technology, vol. 120, pp. 289-295, 2013.

[27] H. Ouni and M. Dhahbi, "Spectrometric study of crystal violet in presence of polyacrylic acid and polyethylenimine and its removal by polyelectrolyte enhanced ultrafiltration," Separation and Purification Technology, vol. 72, no. 3, pp. 340-346, 2010.

[28] S. Barredo-Damas et al., "Application of nanofiltration/reverse osmosis membranes to textile effluents aiming its reclamation and reuse: influence of operating conditions," Chemical Engineering Transactions, vol. 21, pp. 1027-1032, 2010.

[29] M. R. Hoffmann, S. T. Martin, W. Choi, and D. W. Bahnemann, "Environmental applications of semiconductor photocatalysis," Chemical Reviews, vol. 95, no. 1, pp. 69-96, 1995.

[30] M. Sulak, E. Demirbas, and M. Kobya, "Removal of Astrazon Yellow 7GL from aqueous solutions by adsorption onto wheat bran," Bioresource Technology, vol. 98, no. 13, pp. 2590-2598, 2007.

[31] K. Xie, W. Zhao, and X. He, “Adsorption properties of nanocellulose hybrid containing polyhedral oligomeric silsesquioxane and removal of reactive dyes from aqueous solution," Carbohydrate Polymers, vol. 83, no. 4, pp. 1516-1520, 2011. 
[32] M. J. Iqbal and M. N. Ashiq, "Adsorption of dyes from aqueous solutions on activated charcoal," Journal of Hazardous Materials, vol. 139, no. 1, pp. 57-66, 2007.

[33] Z. A. ALOthman, M. Naushad, and R. Ali, "Kinetic, equilibrium isotherm and thermodynamic studies of $\mathrm{Cr}$ (VI) adsorption onto low-cost adsorbent developed from peanut shell activated with phosphoric acid," Environmental Science and Pollution Research, vol. 20, no. 5, pp. 3351-3365, 2013.

[34] A. M. Aljeboree, A. N. Alshirifi, and A. F. Alkaim, "Kinetics and equilibrium study for the adsorption of textile dyes on coconut shell activated carbon," Arabian Journal of Chemistry, vol. 10, pp. S3381-S3393, 2017.

[35] A. S. Franca, L. S. Oliveira, and M. E. Ferreira, "Kinetics and equilibrium studies of methylene blue adsorption by spent coffee grounds," Desalination, vol. 249, no. 1, pp. 267-272, 2009.

[36] M. T. Yagub, T. K. Sen, S. Afroze, and H. M. Ang, "Dye and its removal from aqueous solution by adsorption: a review," Advances in Colloid and Interface Science, vol. 209, pp. 172184, 2014.

[37] U. Shedbalkar and J. P. Jadhav, "Detoxification of malachite green and textile industrial effluent by Penicillium ochrochloron," Biotechnology and Bioprocess Engineering, vol. 16, no. 1, pp. 196-204, 2011.

[38] T. Hadibarata, A. R. M. Yusoff, A. Aris, Salmiati, T. Hidayat, and R. A. Kristanti, "Decolorization of azo, triphenylmethane and anthraquinone dyes by laccase of a newly isolated armillaria sp. F022," Water, Air, \& Soil Pollution, vol. 223, no. 3, pp. 1045-1054, 2012.

[39] M. Zheng, Y. Chi, H. Yi, and S. Shao, "Decolorization of Alizarin Red and other synthetic dyes by a recombinant laccase from Pichia pastoris," Biotechnology Letters, vol. 36, no. 1, pp. 39-45, 2014.

[40] C. M. Radetski, S. M. C. Rosa, E. V. C. Rosa, M. M. De Souza Sierra, and E. L. Simionatto, "Ozonation of textile wastewater: physico-chemical and phytotoxic aspects," Environmental Technology, vol. 23, no. 5, pp. 537-545, 2002.

[41] O. S. G. P. Soares, J. J. M. Órfão, D. Portela, A. Vieira, and M. F. R. Pereira, "Ozonation of textile effluents and dye solutions under continuous operation: influence of operating parameters," Journal of Hazardous Materials, vol. 137, no. 3, pp. 1664-1673, 2006.

[42] M. Punzi, F. Nilsson, A. Anbalagan et al., "Combined anaerobic-ozonation process for treatment of textile wastewater: removal of acute toxicity and mutagenicity," Journal of Hazardous Materials, vol. 292, pp. 52-60, 2015.

[43] M. Nie, "Understanding plant-microbe interactions for phytoremediation of petroleum-polluted soil," PLoS One, vol. 6, no. 3, Article ID e17961, 2011.

[44] C. O. Nwoko, "Trends in phytoremediation of toxic elemental and organic pollutants," African Journal of Biotechnology, vol. 9, no. 37, pp. 6010-6016, 2010.

[45] A. C. Dietz and J. L. Schnoor, "Advances in phytoremediation," Environmental Health Perspectives, vol. 109, no. 1, pp. 163-168, 2001. 